\title{
Deletion of high-molecular-weight glutenin subunits in wheat significantly reduced dough strength and bread-baking quality
}

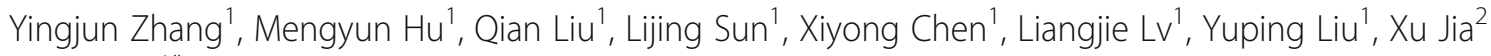
and Hui $\mathrm{Li}^{1 *}$ (D)

\begin{abstract}
Background: High-molecular-weight glutenin subunits (HMW-GS) play important roles in the elasticity of dough made from wheat. The HMW-GS null line is useful for studying the contribution of HMW-GS to the end-use quality of wheat.

Methods: In a previous work, we cloned the Glu-1Eb gene from Thinopyrum bessarabicum and introduced it into the wheat cultivar, Bobwhite. In addition to lines expressing the Glu-1 $E^{b} \times$ gene, we also obtained a transgenic line (LH-11) with all the HMW-GS genes silenced. The HMW-GS deletion was stably inherited as a dominant and conformed to Mendel's laws. Expression levels of HMW-GS were determined by RT-PCR and epigenetic changes in methylation patterns and small RNAs were analyzed. Glutenins and gliadins were separated and quantitated by reversed-phase ultra-performance liquid chromatography. Measurement of glutenin macropolymer, and analysis of agronomic traits and end-use quality were also performed.

Results: DNA methylation and the presence of small double-stranded RNA may be the causes of post-transcriptional gene silencing in LH-11. The accumulation rate and final content of glutenin macropolymer (GMP) in LH-11 were significantly lower than in wild-type (WT) Bobwhite. The total protein content was not significantly affected as the total gliadin content increased in LH-11 compared to WT. Deletion of HMW-GS also changed the content of different gliadin fractions. The ratio of $\omega$-gliadin increased, whereas $\alpha / \beta$ - and $\gamma$-gliadins declined in LH-11. The wet gluten content, sedimentation value, development time and stability time of $\mathrm{LH}-11$ were remarkably lower than that of Bobwhite. Bread cannot be made using the flour of $\mathrm{LH}-11$.

Conclusions: Post-transcriptional gene silencing through epigenetic changes and RNA inhibition appear to be the causes for the gene expression deficiency in the transgenic line LH-11. The silencing of HMW-GW in LH-11 significantly reduced the dough properties, GMP content, wet gluten content, sedimentation value, development time and stability time of flour made from this wheat cultivar. The HMW-GS null line may provide a potential material for biscuit-making because of its low dough strength.
\end{abstract}

Keywords: Common wheat, High-molecular-weight glutenin subunits, Post-transcriptional gene silencing, Glutenin macropolymer, Gliadin content, Dough quality

\footnotetext{
* Correspondence: zwslihui@163.com

${ }^{1}$ Institute of Cereal and Oil Crops, Hebei Academy of Agriculture and Forestry

Sciences, 162 Hengshan Street, Shijiazhuang 050035, China

Full list of author information is available at the end of the article
}

(c) The Author(s). 2018 Open Access This article is distributed under the terms of the Creative Commons Attribution 4.0 International License (http://creativecommons.org/licenses/by/4.0/), which permits unrestricted use, distribution, and reproduction in any medium, provided you give appropriate credit to the original author(s) and the source, provide a link to the Creative Commons license, and indicate if changes were made. The Creative Commons Public Domain Dedication waiver (http://creativecommons.org/publicdomain/zero/1.0/) applies to the data made available in this article, unless otherwise stated. 


\section{Background}

Wheat (Triticum aestivum L.) is a staple crop grown widely in the world as a source of flour for various kinds of foods due to the presence of gluten proteins in its seeds. Gluten is commonly classified into glutenins and gliadins. Gliadins are responsible for the extensibility and viscosity of dough [1]. Glutenins are of two major types: high-molecular-weight glutenin subunits (HMW-GS) and low-molecular-weight glutenin subunits (LMW-GS), both of which affect the strength and elasticity of wheat dough [2]. It was reported that HMW-GS constitute linear chains and protein networks, while LMW-GS exist as clusters and aggregates formed by branching from linear chains. Gliadins are equally spread throughout the dough, exhibiting 'space-filling' roles [3], whereas, the HMW-GS are the major factors affecting the end-use quality of wheat $[1,4]$.

The HMW-GS are encoded by Glu-A1, Glu-B1, and Glu-D1 which are located at the Glu-1 loci on the long arms of chromosomes $1 \mathrm{~A}, 1 \mathrm{~B}$ and $1 \mathrm{D}$, respectively [5]. Each locus is comprised of two tightly linked genes encoding an $\mathrm{x}$-type and a y-type subunit which have different electrophoretic mobilities [1]. In theory, there should be six HMW-GS (including 1Ax, 1Ay, 1Bx, 1By, 1Dx, and $1 \mathrm{Dy}$ ) in hexaploid common wheat. Owing to the silencing of some HMW-GS genes, only three to five subunits are present in an individual common wheat variety [6]. For example, genes $1 B x, 1 D x$, and $1 D y$ are normally expressed, whereas $1 A y$ is often not expressed in common wheat [7]. The HMW-GS have many repeat units such as nona- (GYYPTSL/PQQ), hexa- (PGQGQQ) and tri-peptides (GQQ) in the central repetitive domain. The central domain is flanked by two highly conserved non-repetitive $\mathrm{N}$ - and $\mathrm{C}$-terminal domains that are rich in charged residues [8]. It is demonstrated that the central repetitive domain constitutes $\beta$-turns, while both the $\mathrm{N}$ - and $\mathrm{C}$-terminal domains are rich in $\alpha$-helices by molecular modeling and secondary structural analyses [9, 10]. Since the disulphide bonds between the cysteine residues affect the conformation and structure of the protein, the number and distribution of cysteines in each of the three domains of HMW-GS are particularly interesting. Most cysteines are in the terminal domains. Normally, there is only one conserved cysteine in the C-terminus, while there are three and five conserved cysteine residues in the $\mathrm{N}$-terminal domain of the larger $x$-type subunits and the smaller y-type subunits, respectively [11]. These are the most crucial features of the glutenins associated with the physical properties of wheat dough [12].

The discovery of HMW-GS from wheat relative species not only enhances end-use quality but also broadens the genetic diversity. Many studies have focused on different landraces, wild species and wheat relatives $[4,13]$ because they provide abundant diversity of Glu-1 loci in comparison with bread wheat. People have identified 22 alleles for Glu-A1, 52 for Glu-B1 and 36 for Glu-D1 based on the Grain Genes 2.0 database [7]. For example, the Glu-R1 locus of rye [14], Glu-E1 locus of Elytrigia elongata [15], Glu-V1 locus of Dasypyrum villosum [16, 17], Glu-U1 locus of Aegilops umbellulata [18] and Glu-C1 locus of Aegilops caudata [19] have been presumed or confirmed to be the loci of interest encoding HMW-GS corresponding to wheat.

The combinations of HMW-GS subunits are thought to account for up to $70 \%$ of the good bread-making qualities of wheat $[20,21]$. The Glu-D1 locus has the largest effect on the rheological properties and dough quality of the wheat flour [22]. As an important breeding strategy, scientists try to aggregate superior HMW-GS together to improve wheat dough quality. The cultivars with a combination of $1 D x 5+1 D y 10$ have suitable viscoelastic properties for good loaf volume [23, 24]. The $1 A \times 2^{*}$ at Glu-A1 is related to greater dough strength and better bread-baking [25]. The $1 B x 17+1 B y 18,1 B x 13+1 B y 16$ and $1 B x 7+1 B y 8$ at Glu-B1 show higher elastic moduli and viscosity coefficients which have positive effects on bread volume [26, 27]. However, their allelic variants such as $1 A x$ null, $1 B x 6+1 B y 8$, and $1 D x 2+1 D y 12$ are associated with poor baking quality [28-31]. The effects of different subunits on dough quality may be due to their molecular weight and the number of cysteine residues. There are more cysteines in the $y$-type subunits than $x$-type, making y-type subunits more important for baking quality improvement because of their greater abilities to form interand intra-chain disulphide bonds [32]. An extra cysteine residue in the $\mathrm{N}$-terminal domain of $1 D \times 5$ enhances dough elasticity, whereas two less cysteines in $1 B \times 20$ reduces wheat dough strength $[4,33,34]$.

Each glutenin subunit accounts for about $2 \%$ of the total grain protein and the differences in gene expression could result in quantitative effects on total HMW-GS content, which in turn affects processing quality. For example, increasing the $1 \mathrm{Dx} 5$ or $1 \mathrm{Dy} 10$ subunits and the naturally duplicated $1 B x 7$ gene $\left(B x 7^{O E}\right)$ led to better dough strength $[35,36]$. On the other hand, wheat lines with individual HMW-GS deficiencies at the Glu-1 locus were characterized and used to determine the contributions of single HMW-GS on gluten micro structure, glutenin polymerization, dough mixing properties and bread-making quality [37-40]. However, the effect of silencing all the HMW-GS genes on wheat quality has not been studied. In previous work, we have obtained an HMW-GS null line, LH-11, which is of value for analyzing the contributions of HMW-GS to wheat flour processing quality. Therefore, in the current study we had the following objectives: (a) to find out the mechanism behind HMW-GS gene silencing in line LH-11 and (b) to evaluate the effects of deletion of HMW-GS on dough 
structure, gliadin fragments, agronomic traits and end-use quality of wheat.

\section{Results}

HMW-GS are silenced in transgenic line LH-11

The spring wheat variety, Bobwhite, was transformed with the $G l u-1 E^{b} x$ gene. We obtained ten positive transgenic lines expressing the Glu-1E $x$ gene and one transgenic line (LH-11) with all the HMW-GS silenced. None of the HMW-GS were detected in LH-11, including the 5 HMW-GS (1Ax2*,1Bx7, 1By9, 1Dx5 and 1Dy10) of Bobwhite and the $1 \mathrm{E}^{\mathrm{b}} \mathrm{x}$ of Thinopyrum bessarabicum as well, by sodium dodecyl sulphate polyacrylamide gel electrophoresis (SDS-PAGE) (Fig. 1a). RT-PCR was carried out to determine the expression level changes of HMW-GS genes (Glu-1) between wild-type Bobwhite and line LH-11. Total RNA was isolated from the seeds of LH-11 and wild-type Bobwhite at 6, 9, 12, 15, 18 and 21 days after flowering (DAF), reverse-transcribed to cDNA and amplified by PCR. The $\beta$-tubulin gene had the same PCR amplification level across all samples, indicating the cDNA of all the samples were at equal concentrations (Fig. 2). There were five HMW-GS, namely $1 \mathrm{Ax} 2 *, 1 \mathrm{Bx} 7,1 \mathrm{By} 9,1 \mathrm{Dx} 5$ and 1Dy10, in Bobwhite that were encoded by genes Glu-1Ax2*, Glu-1Bx7, Glu-1By9, Glu-1Dx5, and Glu-1Dy10, respectively. All five Glu-1 genes were completely blocked in the seeds of LH-11 except weak signals of Glu-1Ax2* in seeds at 15 DAF and Glu- $1 B x 7$ in seeds at 18 DAF, whereas they were strongly expressed in seeds of wild-type Bobwhite. However, Glu-1E $E^{b} x$ was expressed normally in LH-11. The expression of HMW-GS genes were obviously silenced or drastically inhibited by the Glu-1E $E^{b} x$ gene in transgenic line LH-11.

\section{DNA methylation and small RNAs were involved in silencing of HMW-GS}

In order to find out what caused silencing of HMW-GS in LH-11 seeds, we performed analyses for DNA methylation and small RNAs. DNA methylations were detected in the Glu-1Bx7, Glu-1Dx5, Glu-1Dy10 and Glu-1E $E^{b} x$ genes of LH-11. The four genes showed different banding patterns when digested with HpaII or MspI (Fig. 3). DNA was cut more thoroughly with $M s p$ I and smaller fragments were achieved with MspI than with HpaII, demonstrating that all four genes had significant DNA methylations. We then selected the Glu-1Dy10 gene, which had the lowest RNA expression level as an example to carry out small RNA analysis. Two hybridization signals of small RNAs were detected in LH-11, whereas no signals were detected in Bobwhite (Fig. 4). The lengths of the two small RNAs were 20-25 nt; so, it seemed that the silencing of HMW-GS in transgenic line LH-11 was caused by both DNA methylation and small RNAs.
Deletion of HMW-GS in LH-11 is inherited like a dominant trait

To study the inheritance of line LH-11, we crossed LH-11 with five Chinese cultivars (Jinfeng5365, Gao8901, Luozhen1, Gao9411, and Kenong122), respectively. SDS-PAGE was performed to analyze the HMW-GS in $F_{1}$ generation progenies. No HMW-GS were detected in any of the $F_{1}$ generation progenies. The $F_{1}$ was self-crossed to give rise to an $F_{2}$ generation. Of these offspring, about $3 / 4$ had no HMW-GS while 1/4 had HMW-GS; the ratio of segregation was 3:1 (Additional file 1: Table S1). The results showed that HMW-GS gene silencing was dominantly controlled and stably inherited in progenies according to a Mendelian pattern.

\section{Silencing of HMW-GS directly affected the accumulation of glutenin macropolymer (GMP) in LH-11 during seed development}

Seeds at different development stages of $5,10,15,20$, 25, 30 and 35 DAF were taken to carry out GMP analysis. The accumulation of GMP showed a regular increase during seed development (Fig. 5). After slow growth in the early stage of seed development (from 5 to 10 DAF), GMP content increased rapidly from 10 to 25 DAF, slightly decreased from 25 to 30 DAF, and reached its highest value at the mature stage. The GMP content of Bobwhite was similar to that of LH-11 during the early development period (from 5 to $10 \mathrm{DAF}$ ), whereas at the two rapid accumulation stages (10-25 DAF and 30-35 DAF), the accumulation rate of GMP in LH-11 was significantly lower than that in Bobwhite. Furthermore, the final content of GMP in LH-11 was much lower than that in Bobwhite-about half.

\section{Total gliadin content and proportion of $\omega$-gliadin were increased in the LH-11 line}

There was no difference in total protein content between LH-11 and Bobwhite (Table 1). Reversed-phase ultra-performance liquid chromatography (RP-UPLC) was employed to determine the effects of the absence of HMW-GS on LMW-GS and gliadin content. All the HMW-GS were thoroughly silenced (Fig. 1b). The peak area of LMW-GS in LH-11 (2714.4 \pm 46.2$)$ was decreased compared to Bobwhite $(3127.6 \pm 51.3)$, whereas total gliadin content significantly increased in LH-11 (Fig. 1c). Deletion of HMW-GS also caused changes in the percentage content of different gliadins fragments. The ratio of $\omega$-gliadin increased from 20.5 to $25.8 \%$, however, $\alpha / \beta$-gliadin and $\gamma$-gliadin declined from 54.3 to $50.7 \%$ and 25.2 to $23.5 \%$, respectively (Table 2 ).

\section{Plant height and seed number increased in LH-11}

To investigate the effects of deletion of HMW-GS on agronomic traits of $\mathrm{LH}-11$, we measured the plant 


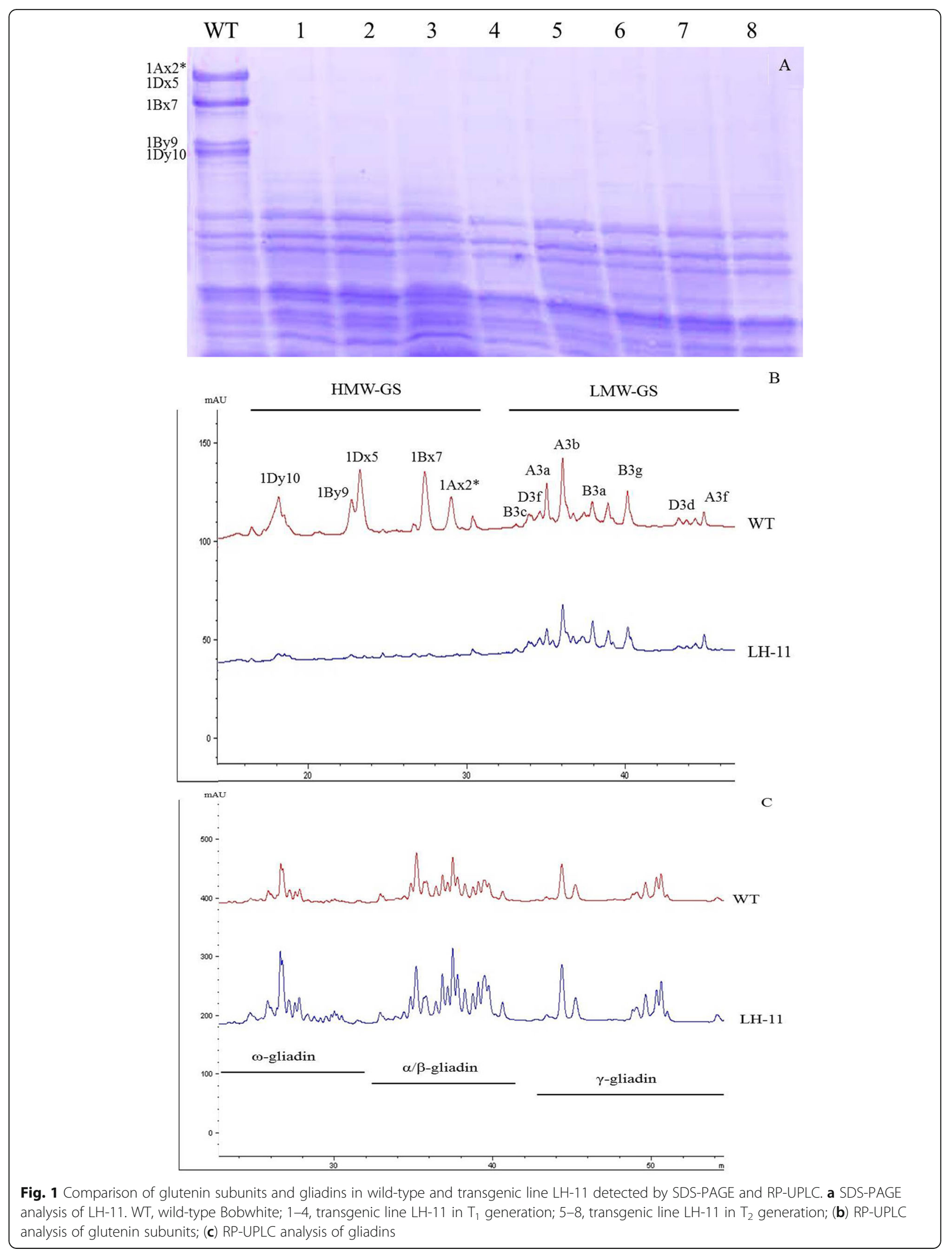




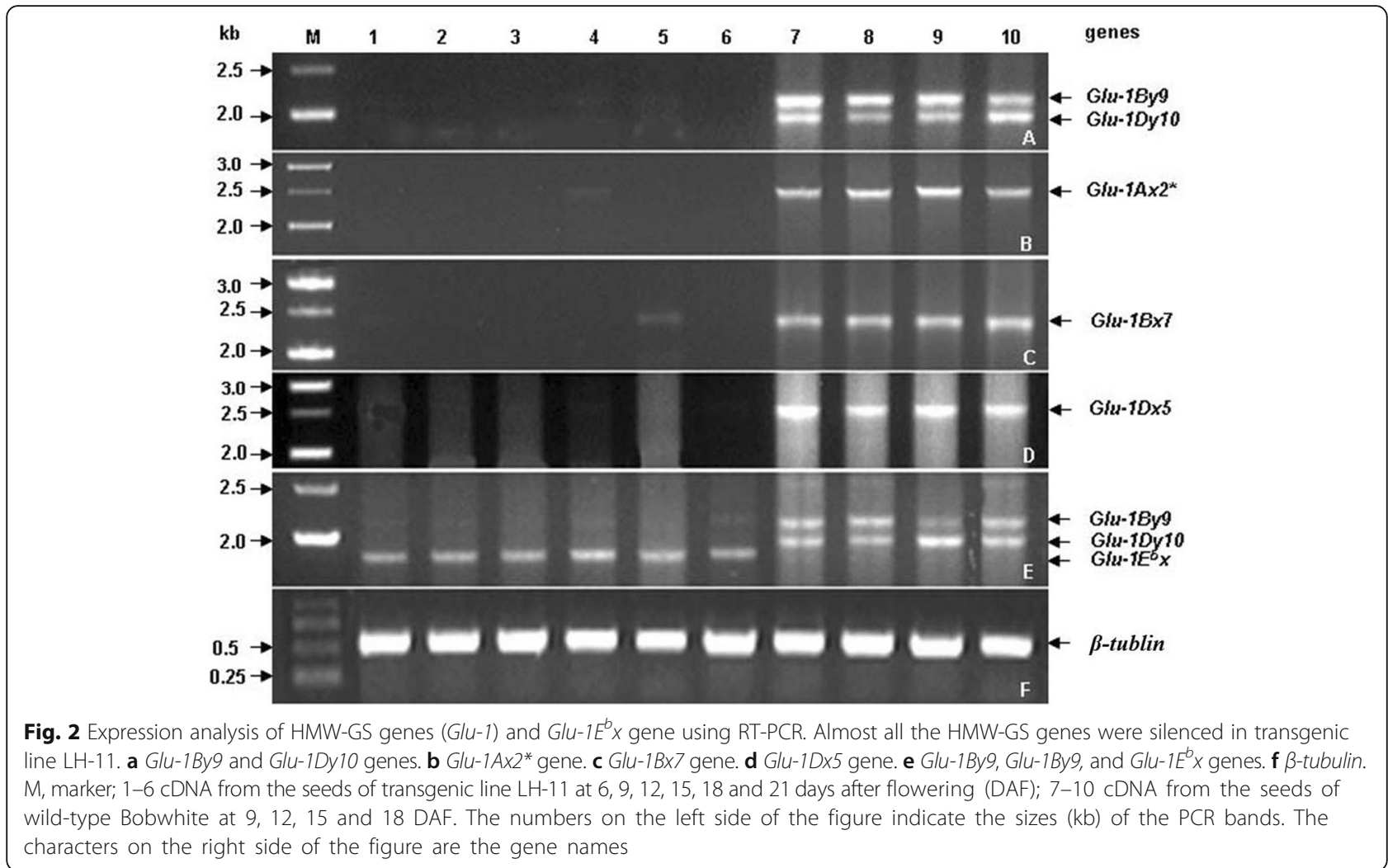

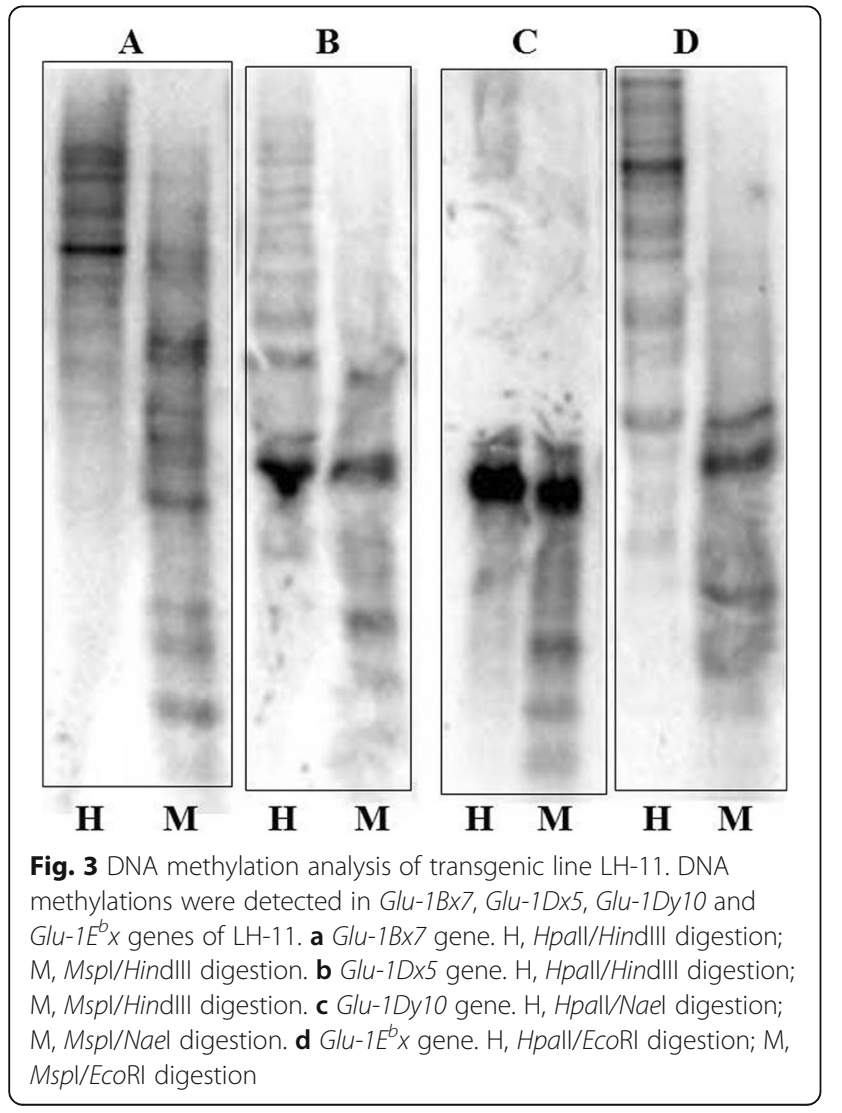

height, panicle number, and seed number among other factors (Table 3). The plant height, spike length, seeds per panicle and seeds per plant in LH-11 were significantly greater than in wild-type Bobwhite. The height of LH-11 increased by $7 \%$ and the seed numbers per plant increased drastically from 160.5 in Bobwhite to 198.8 in LH-11 (23.9\% increase). The panicle and tiller numbers per plant increased slightly, whereas the floret numbers decreased slightly in LH-11, but the differences did not reach a significant level $(P<0.05)$.

\section{Bread-baking quality of LH-11 was significantly reduced}

The differences in rheological and farinograph properties of dough from LH-11 compared to Bobwhite were measured. Wet gluten content, sedimentation value, water absorption, development time and stability time in LH-11 decreased significantly $(P<0.01)$ compared to Bobwhite. The wet gluten content in LH-11 was reduced so much (from 31.0 to $3.4 \%$ ) that the development time and stability time were very short: the development time decreased from 6.0 to $0.4 \mathrm{~min}$, and the stability time from 7.0 to $0.6 \mathrm{~min}$ (Table 1). Bread cannot be made successfully from the flour of LH-11.

\section{Discussion}

It has been accepted that the variation in HMW-GS composition strongly affects wheat processing quality. 


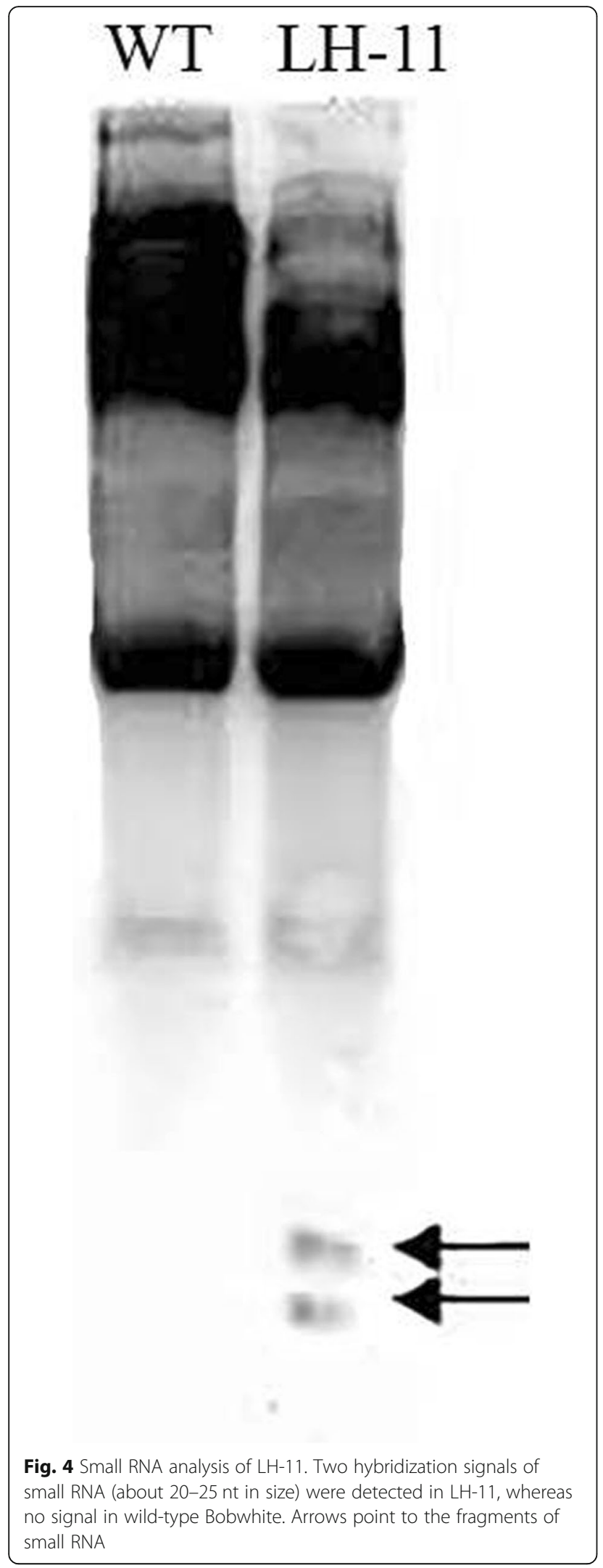

Lines exhibiting no expression of HMW-GS such as LH-11 described here can provide wheat breeders with new materials to study end-use functionality. In this study, a transgenic line LH-11 with all the HMW-GS silenced was obtained in addition to ten positive transgenic lines expressing the $G l u-1 E^{b} x$ gene. In LH-11, none of the HMW-GS including the five endogenous HMW-GS of the donor plant, Bobwhite, and the $1 \mathrm{E}^{\mathrm{b}} \mathrm{x}$ of Th. Bessarabicum were detectable by SDS-PAGE (Fig. 1a). Our results showed that $\mathrm{LH}-11$ was a stable line and the trait of deletion of HMW-GS was inherited by the progenies. LH-11 was crossed with five Chinese wheat cultivars. All the $F_{1}$ seeds and $3 / 4$ of the $F_{2}$ seeds had deletions of HMW-GS (Additional file 1: Table S1), showing that it followed Mendel's dominant gene inheritance law.

In transgenic line LH-11, Glu- $1 E^{b} x$ was transcribed successfully into RNA, but it was not translated into protein. All of the five homologous endogenous Glu-1 genes (Glu-1Ax2*, Glu-1Bx7, Glu-1By9, Glu-1Dx5 and Glu-1Dy10) in Bobwhite were degraded at the RNA level (Fig. 2), which meant that post-transcriptional gene silencing (PTGS) was triggered in LH-11. PTGS is thought to be a universal gene regulation system in biological processes including defense against viruses and regulation of gene expression [41]. PTGS mostly occurs when the exogenous gene is homologous to the endogenous gene [42]. This phenomenon was first discovered in 1990 and is also called 'co-suppression' because the expression of both the introduced and the homologous endogenous genes were suppressed together [43, 44]. Because of co-suppression, silencing of endogenous HMW-GS after transformation has been commonly detected in wheat lines that contain HMW-GS transgenes designed for over-expression [45-47]. We postulated that PTGS was occurring in LH-11 either because of DNA methylation or the presence of small, double-stranded (ds) RNAs.

There are two main mechanisms for how DNA methylation inhibits gene expression. First, modification of cytosine bases can directly prevent transcription factors from binding to DNA recognition sequences [48, 49]. Second, DNA methylation results in chromatin modification and remodeling through the action of methyl-cytosine binding proteins (MBPs) and histone deacetylases [50, 51]. Here we showed that there were different degrees of DNA methylation in four genes Glu-1Bx7, Glu-1Dx5, Glu-1Dy10 and $G l u-1 E^{b} x$, indicating that DNA methylation may cause gene silencing in LH-11 (Fig. 3). Double-stranded RNA is another trigger of PTGS. Plants can recognize dsRNAs from transgenes or viruses and cut them into short RNAs (21-26 nt) such as small interfering RNAs (siRNAs) and microRNAs (miRNAs) with an enzyme called Dicer [5255]. The miRNAs and siRNAs are incorporated into the 

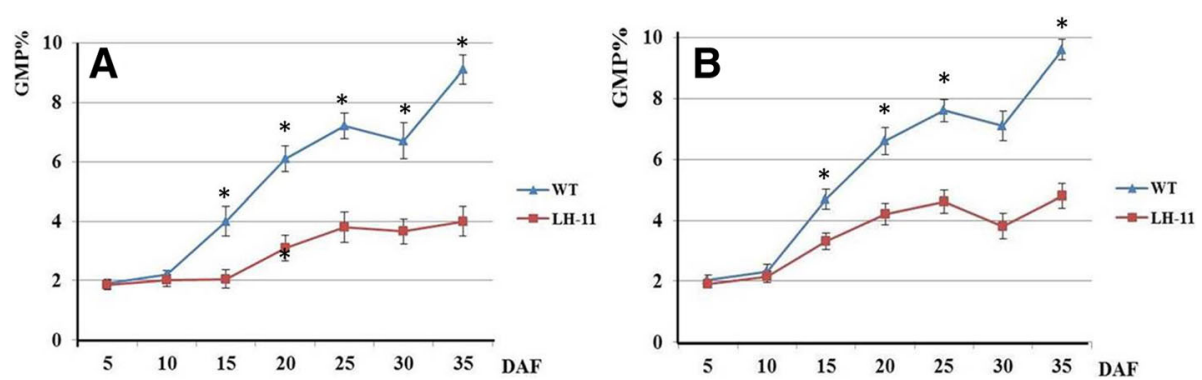

Fig. 5 Accumulations of GMP during seed development in wild-type Bobwhite and transgenic line LH-11. a year 2008; b year 2009. WT, wild-type Bobwhite. Statistical significance was determined by a Student's $t$-test at $P<0.01$

RNA-induced silencing complex (RISC) resulting in transcript cleavage [56, 57]. Researchers have detected significant accumulations of siRNAs in various PTGS systems in plants [58], so endogenous small RNAs may also play key roles in regulating gene expression and causing PTGS [59]. We isolated total RNA from $\mathrm{T}_{4}$ generation seeds of LH-11 and separated the small RNAs. Northern blots using Glu-1Dy10 RNA as probe gave two hybridization signals of small RNAs in LH-11, whereas no signal was detected in wild-type Bobwhite (Fig. 4). Thus, small RNAs may be another way that HMW-GS are silenced in LH-11.

Although they represent only $10 \%$ of wheat storage proteins, HMW-GS have been recognized as crucial factors in determining the viscoelastic properties of wheat dough [60]. The physical properties of dough stem from interactions between HMW-GS and other grain storage proteins via both inter- and intra-chain disulphide bonds forming glutenin macropolymers (GMP) which contribute to the elasticity and strength of dough [4]. It has been reported that the $\mathrm{x}$ - and $\mathrm{y}$-type HMW-GS are linked via head-to-tail disulphide bonds to form a backbone of the polymer. The LMW-GS constitute branch points of the y-type subunits at four positions [61]. Because the cysteine residues of HMW-GS affect polymeric behavior $[9,62]$, the composition and quantity of HMW-GS significantly affect the particle size and amount of GMP in flour [63]. Loss of HMW-GS from the polymer is always consistent with the time of dough breakdown. [1]. In this study, we analyzed the dynamic change of GMP at different seed development stages of the wild-type Bobwhite and transgenic line LH-11. The accumulation rate of GMP in LH-11 was significantly lower than that in Bobwhite at 10-25 and 30-35 DAF, which resulted in the final content of GMP in LH-11 being only half of that in Bobwhite (Fig. 5). Because HMW-GS is necessary for the formation of the dough protein network, the absence of HMW-GS resulted in the formation of 'sheets' in dough rather than a three-dimensional structure [64]. The decrease in GMP content may be one of the reasons for the decline in wheat flour quality of LH-11.

In addition to the HMW-GS, gliadins also play important roles in determining end-use wheat quality. Gliadins account for about $50 \%$ of seed storage proteins and generally contribute to the extensibility and viscosity of wheat dough [65]. The gliadins are divided into three types: $\alpha / \beta-, \gamma^{-}$and $\omega$-gliadins [66]. Unlike glutenins which form polymers by both inter- and intra-chain disulphide bonds, gliadins are monomeric proteins that contain only intra-chain bonds (Shewry and Halford, 2003). Differences in the disulphide bonding properties of glutenins and gliadins affect how they establish the GMP and gluten structures. Our results showed that silencing of HMW-GS increased the total gliadin content in LH-11 (Table 2). It is generally agreed that total gliadin content has a significant negative correlation with dough properties such as development time and stability time [67]. In the present study, we checked gliadin levels in LH-11 by RP-UPLC and found that increase in total gliadin content may be another reason of bread-baking quality breakdown besides the absence of HMW-GS in LH-11. Deletion of HMW-GS also caused changes in the percentage content of different gliadins fractions. The ratio of $\omega$-gliadin increased, whereas $\alpha / \beta$ - and $\gamma$-gliadins declined in LH-11 (Table 2). Different types of gliadins have different effects on wheat quality depending on their

Table 1 Rheological analysis of dough from transgenic line LH-11

\begin{tabular}{|c|c|c|c|c|c|c|c|c|}
\hline Material & TP\% & WG\% & SV (ml) & WA\% & DT (min) & $\mathrm{ST}$ (min) & $\mathrm{BV}(\mathrm{ml})$ & BS \\
\hline Bobwhite & $15.4 \pm 0.2$ & $31.0 \pm 1.6^{*}$ & $28.8 \pm 0.8^{*}$ & $61.8 \pm 1.7^{*}$ & $6.0 \pm 0.3^{*}$ & $7.0 \pm 0.3^{*}$ & $770.0 \pm 23.2^{*}$ & $74.0 \pm 2.2^{*}$ \\
\hline LH-11 & $15.0 \pm 0.3$ & $3.4 \pm 0.2$ & $6.8 \pm 0.2$ & $55.0 \pm 1.4$ & $0.4 \pm 0.1$ & $0.6 \pm 0.1$ & & \\
\hline
\end{tabular}

* Statistical significance was determined by a Student's $t$-test at $P<0.01$

$T P$ total protein content, WG wet gluten content, SV sedimentation value, WA water absorption, $D T$ development time, $S T$ stability time, $B V$ bread volume, $B S$ bread score 
Table 2 Relative content of glutenins and gliadins by RP-UPLC

\begin{tabular}{llllllll}
\hline & HMW-GS\% & LMW-GS\% & Glutenins $^{\mathrm{a}}$ & w-gliadin\% & a/B-gliadin\% & y-gliadin\% Gliadins $^{\mathrm{a}}$ \\
\hline Bobwhite & $48.8 \pm 1.2^{* *}$ & $51.2 \pm 0.9^{* *}$ & $6112.3 \pm 128.3^{* *}$ & $20.5 \pm 0.7^{*}$ & $54.3 \pm 1.3^{*}$ & $25.2 \pm 0.5^{*}$ & $17,775.0 \pm 689.3^{* *}$ \\
LH-11 & 0 & 100 & $2714.6 \pm 46.2$ & $25.8 \pm 1.1$ & $50.7 \pm 1.4$ & $23.5 \pm 0.6$ & $30,017.1 \pm 942.2$ \\
\hline
\end{tabular}

${ }^{a}$ The peak area $(1000 \mathrm{uV} / \mathrm{S})$ of total glutenins and gliadins*Statistical significance was determined by a Student's $t$-test at $P<0.05^{* *}$ Statistical significance was determined by a Student's $t$-test at $P<0.01$

properties. The $\omega$-gliadins lack cysteine and cannot form disulphide bonds. The $\alpha / \beta$-gliadins contain six cysteine residues and $\gamma$-gliadins contain eight cysteine residues [66]. Furthermore, $\omega$-gliadins have a $\beta$-turn structure, while $\alpha / \beta$ - and $\gamma$-gliadins have a high proportion of $\alpha$-helical and $\beta$-sheet structures [9]. The $\omega$-gliadins are sulphur-poor, while, $\alpha / \beta$ - and $\gamma$-gliadins are sulphur-rich protein. Some studies indicated that $\alpha / \beta$-gliadins and $\gamma$-gliadins were positively associated with loaf volume and development time, respectively $[67,68]$. The increase in the proportion of $\omega$-gliadins and decrease in both $\alpha / \beta$ and $\gamma$-gliadins in LH-11 also reduced dough quality. The total protein content was not significantly affected in LH-11 comparing to Bobwhite (Table 1). The reduction of glutenins was compensated for by increasing gliadin content in the grain, suggesting that wheat has a good system for balancing gluten proteins [69]. The wet gluten content and sedimentation value in LH-11 were much lower than that of the wild-type (Table 1). Development time and stability time are closely linked to dough strength. Results reported in the present study showed that the average development time and stability time in LH-11 were remarkably lower than in Bobwhite (Table 1). The flour of LH-11 is unsuitable for bread-making, but has great potential for making biscuits because of its low dough strength.

\section{Conclusions}

In the transgenic wheat line LH-11, all the HMW-GS were silenced and this genetic modification was stably passed on to progenies by crossing LH-11 with other wheat cultivars. We found DNA methylations and small RNA signals in HMW-GS genes of LH-11, indicating that DNA methylation and double-stranded RNA may be the reasons for post-transcriptional gene silencing in LH-11. The silencing of HMW-GS in LH-11 significantly altered its dough properties. The accumulation rate of GMP at the rapid accumulation stages (10-25 DAF and 30-35 DAF) and final content of GMP in LH-11 were much lower than in wild-type Bobwhite. The content of LMW-GS decreased whereas total gliadin content significantly increased in LH-11 compared to the wild-type. Deletion of HMW-GS also caused changes in the percentage content of different gliadins fragments. The ratio of $\omega$-gliadin increased from 20.5 to $25.8 \%$, however, $\alpha / \beta$-gliadin and $\gamma$-gliadin declined from 54.3 to $50.7 \%$ and 25.2 to $23.5 \%$, respectively. The wet gluten content and sedimentation value of LH-11 were remarkably lower than that of Bobwhite. The development time decreased from 6.0 to $0.4 \mathrm{~min}$ and the stability time from 7.0 to $0.6 \mathrm{~min}$. Therefore, flour from LH-11wheat has good potential for biscuit-making because of its low dough strength.

\section{Methods \\ Plant materials}

In a previous study, we cloned the Glu- $1 E^{b} x$ gene (GenBank accession AY525782) encoding HMW-GS of Th. Bessarabicum and introduced it into the common wheat cultivar, Bobwhite, using a biolistic transformation method. Besides ten transgenic events characterized by expression of the $G l u-1 E^{b} x$ gene, we also, fortunately obtained a transgenic line, LH-11, with all HMW-GS silenced. $\mathrm{LH}-11$ is in the $\mathrm{T}_{6}$ generation now and the trait of deletion of all HMW-GS is still stably inherited. To study the genetic inheritance of LH-11, we crossed it with five Chinese wheat cultivars (Jinfeng5365, Gao8901, Luozhen1, Gao9411, and Kenong122), respectively. The $F_{1}$ was self-crossed to give rise to $F_{2}$ generation. The field trials in the present study were carried out in randomized complete blocks with three replicates at Shijiazhuang, Hebei province, China.

\section{Analysis of expression levels of HMW-GS genes in LH-11} Total RNA was isolated (three biological replicates) from the seeds of positive transgenic lines and wild-type Bobwhite at $6,9,12,15,18$ and 21 days after flowering (DAF) using the Trizol method (www.tiangen.com). All samples were DNase-treated before reverse transcription. The first-strand cDNA was synthesized by MMLV reverse transcriptase (http://www.promega.com.cn) using oligo $(\mathrm{dT})$ as a primer. Reverse transcriptional

Table 3 Agronomic traits of LH-11 and Bobwhite

\begin{tabular}{|c|c|c|c|c|c|c|c|}
\hline Material & Plant height & Panicles per plant & Tiller number & Spike length & Floret number & Seeds per panicle & Seeds per plant \\
\hline LH-11 & $74.79 \pm 1.5^{*}$ & $3.3 \pm 0.4$ & $5.1 \pm 0.2$ & $10.5 \pm 0.4^{*}$ & $81.9 \pm 7.5$ & $59.9 \pm 4.1^{*}$ & $198.8 \pm 4.9^{*}$ \\
\hline Bobwhite & $69.4 \pm 1.2$ & $3.0 \pm 0.3$ & $4.9 \pm 0.8$ & $9.9 \pm 0.1$ & $83.6 \pm 2.2$ & $53.6 \pm 1.4$ & $160.5 \pm 7.7$ \\
\hline
\end{tabular}

* Statistical significance was determined by a Student's $t$-test at $P<0.05$ 
products were adjusted to an equal concentration according to the PCR signal generated from the internal standard house-keeping gene, $\beta$-tubulin, and used as templates for RT-PCR. The primers used in RT-PCR are listed in Table 4. RT-PCR was performed in total volumes of $20 \mu \mathrm{l}$, including $2 \mu \mathrm{l}$ of $10 \times$ LaTaq buffer, $0.5 \mu \mathrm{l}$ of dNTP (2.5 mM of each dNTP), $1 \mu \mathrm{l}$ of each primer $(5 \mu \mathrm{M}), 1 \mathrm{U}$ of La DNA polymerase and $80 \mathrm{ng}$ of template cDNA. PCR conditions were: initial denaturation at $94{ }^{\circ} \mathrm{C}$ for $3 \mathrm{~min}$, followed by 40 cycles at $94{ }^{\circ} \mathrm{C}$ for $30 \mathrm{~s}$, $58^{\circ} \mathrm{C}$ for $30 \mathrm{~s}$ and $72{ }^{\circ} \mathrm{C}$ for $3 \mathrm{~min}$, and a final extension for $5 \mathrm{~min}$ at $72^{\circ} \mathrm{C}$. RT-PCR products were separated in $1 \%$ agarose gels, and the bands were visualized with ethidium bromide.

\section{DNA methylation analysis}

DNA methylation analyses in this study relied on digestion with methylation-sensitive restriction enzymes followed by gel electrophoresis and hybridization on southern blots. Restriction enzymes MspI and HpaII have the same recognition site CCGG. HapII is a methylation-sensitive restriction enzyme which is inhibited by $5^{\mathrm{me}} \mathrm{C}$ in the sequence context $\mathrm{CpG}$, whereas its isoschizomer MspI is not inhibited by CpG methylation. The patterns of cutting by these two enzymes can provide a read-out of DNA methylation. In $\mathrm{T}_{4}$ generation, we chose four genes Glu-1Bx7, Glu-1Dx5, Glu-1Dy10 and $G l u-1 E^{b} x$ for DNA methylation examination. By analyzing gene sequences of these four genes, we selected different restriction enzymes to do double digests of different genes; HindIII + HpaII/MspI were employed to digest Glu-1Bx7 and Glu-1Dx5, NaeI + HpaII/MspI were used to digest Glu-1Dy10 and EcoRI + HpaII/MspI were used to cut $G l u-1 E^{b} x$, respectively. Genomic DNA (200-500 ng) was cleaved with corresponding restriction enzymes such as HindIII + HpaII or HindIII $+M s p I$ in two separate reactions. Then, the digestion products were separated by electrophoresis on $0.8 \%$ agarose gel

Table 4 Primer sets used in this study

\begin{tabular}{lll}
\hline Primer set & Sequence 5'-3' & Amplified target \\
\hline Ax & F: AGATGACTAAGCGGTTGTTC & The genes of x-type \\
& R: CTGGCTGGCCAACAATGCGT & HMW-GS on Glu-Al locus \\
Bx & F: ATGGCTAAGCGCCTGGTCCT & The genes of x-type \\
& R: TGCCTGGTCGACAATGCGTGC & HMW-GS on Glu-B1 locus \\
Dx & F: ATGGCTAAGCGGTAGTCCT & The genes of x-type \\
& R: CTGGCTGGCCGACAATGCGT & HMW-GS on Glu-D1 locus \\
Y-type & F: ATGGCTAAGCGGTGGTCCT & The genes of y-type \\
& R: GGCTAGCCGACAATGCGTCG & HMW-GS \\
Tublin & F: GGCTAGCCGACAATGCGTCG & B-tubulin gene of wheat \\
& R: GGCTAGCCGACAATGCGTCG & \\
\hline
\end{tabular}

and hybridized using $\left[\alpha-{ }^{32} \mathrm{P}\right] \mathrm{dCTP}$-labelled gene fragment as probes (Additional file 2: Table S2).

\section{Small RNA detection}

Small RNA extraction was performed using the method reported by Peng et al. [70] with minor modifications. Total RNA was isolated from immature $\mathrm{T}_{4}$ generation seeds of line LH-11 using TRNzol reagent (http:// www.tiangen.com/en/). Samples frozen in liquid nitrogen were ground to a fine powder with a mortar and pestle. About $100 \mathrm{mg}$ of powder was transferred into a 2 $\mathrm{ml}$ centrifuge tube containing $1 \mathrm{ml}$ of TRNzol. After being thoroughly mixed by vortexing, the mixture was kept at room temperature for $10 \mathrm{~min}$. Then, $0.2 \mathrm{ml}$ of chloroform was added, the tubes were vortexed vigorously and the mixture was centrifuged at $12,000 \mathrm{rpm}$ for $10 \mathrm{~min}$ at $4{ }^{\circ} \mathrm{C}$. The upper aqueous phase was transferred to a new centrifuge tube and an equal volume of precipitation buffer $(20 \% w / v$ PEG $8000,1 \mathrm{M} \mathrm{NaCl})$ was added. The tubes were incubated at $65^{\circ} \mathrm{C}$ for $15 \mathrm{~min}$, kept at room temperature for $10 \mathrm{~min}$, and chilled on ice immediately for $40 \mathrm{~min}$ to precipitate the high molecular weight RNAs. Following centrifugation at $12,000 \mathrm{rpm}$ for 10 min at $4{ }^{\circ} \mathrm{C}$, the supernatant was collected as the fraction enriched in small RNAs. Small RNAs were precipitated with $1 / 10$ volume of $3 \mathrm{M}$ sodium acetate $(\mathrm{pH} 5.2)$ and 2.5 volume of precooled absolute ethanol at $-20^{\circ} \mathrm{C}$ overnight. The pellet was collected by centrifugation at $12,000 \mathrm{rpm}$ for $20 \mathrm{~min}$ and rinsed twice with $80 \%$ ethanol. Small RNA detection was performed on gene Glu-1Dy10 which was inhibited more thoroughly. Northern blot analysis was carried out according to a standard protocol using $[\alpha-32 \mathrm{P}] \mathrm{dCTP}-$ labelled Glu-1Dy10 RNA as a probe.

\section{Reversed-phase ultraperformance liquid chromatography (RP-UPLC) analysis}

HMW-GS, LMW-GS, and gliadins were extracted from LH-11 ( $\mathrm{T}_{5}$ generation) and wild-type Bobwhite with three biological replicates using published methods [7173]. The quantitative analyses of glutenins and gliadins were made on an Acquity UPLC (Waters Corp.) with a Waters $300 \mathrm{SB}$ C18 column $(50 \times 2.1 \mathrm{~mm}$ i.d., $1.7 \mu \mathrm{m})$. The separation of glutenins was based on the program reported by $\mathrm{Yu}$ et al. [71]. The four eluants were: A, ultrapure water containing $0.06 \%(v / v)$ trifluoroacetic acid (TFA); B, acetonitrile (ACN) containing 0.06\% TFA; C, ultrapure water; and $\mathrm{D}$, methanol. The column was first balanced by increasing the concentration of $\mathrm{B}$ from 21 to $47 \%$ in $15 \mathrm{~min}$. The ratios of $\mathrm{A}$ to $\mathrm{B}$ for weak washing and strong washing needles were $79: 21$ and 53:47\%, respectively. The sample was washed with A from 95 to $5 \%$ and B from 5 to $95 \%$ in $5 \mathrm{~min}$. Final washing was done with solution $\mathrm{C}$ from 90 to $10 \%$ and D from 10 to 
90\% three times within $30 \mathrm{~min}$. The separation conditions of gliadins were taken from the method reported by Han et al. [74]. Two elution buffers were used: solution A was $0.06 \%$ TFA in ultrapure water and solution B was $0.06 \%$ TFA in ACN. The gradient program was set as solution B from 21 to $46 \%$. The differentiations of glutenin and gliadin fractions were based on their elution characteristics. The relative content of each fragment was calculated according to its peak area.

\section{Glutenin macropolymer, agronomic traits, and end-use quality analysis}

Transgenic line LH-11 and wild-type Bobwhite were planted and grown in a completely randomized block design at Shijiazhuang, Hebei province. In the years 2007 through 2008 ( $\mathrm{T}_{3}$ generation) and 2008 through $2009\left(\mathrm{~T}_{4}\right.$ generation), seeds at different development stages $(5,10,15,20,25,30$ and 35 days after flowering (DAF)) were taken to carry out glutenin macropolymer (GMP) analysis according to the method described by Don et al. [75]. Observations on growth and yield-contributing traits $\left(\mathrm{T}_{3}\right.$ generation) such as plant height, number of spikes, number of seeds per plant, etc., were recorded for ten individuals. Dough rheological and farinograph properties of $T_{5}$ generation seeds were used to evaluate the end-use quality. Data were statistically analyzed to find differences between transgenic and wildtype plants using Student's $t$-test. All the tests were performed on three replicates.

\section{Additional files}

Additional file 1: Table S1. Segregation of HMW-GS deletion trait in $F_{1}$ and $F_{2}$ generation offsprings of $\mathrm{LH}-11$. (DOCX $16 \mathrm{~kb}$ )

Additional file 2: Table S2. The probe regions for different genes used for DNA methylation analysis. (DOCX 14 kb)

\section{Abbreviations \\ DAF: Days after flowering; GMP: Glutenin macropolymer; HMW-GS: High- molecular-weight glutenin subunits; LMW-GS: Low-molecular-weight glutenin subunits; PTGS: Post-transcriptional gene silencing; RP- UPLC: Reversed-phase ultra-performance liquid chromatography; RT- PCR: Reverse transcription-polymerase chain reaction; SDS-PAGE: Sodium dodecyl sulphate polyacrylamide gel electrophoresis; WT: Wild-type}

\section{Acknowledgments}

Not applicable.

\section{Funding}

This work was supported by Modern Agricultural Industry Technology System - Hebei Province, Wheat Innovation Team Construction (HBCT2018010201), cultivation of New Wheat Varieties with High Yield, High Quality and Water-saving in North of Yellow and Huai Winter Wheat Region (2017YF00100603), Modern Agricultural Science and Technology Innovation Project of Hebei Province (494-0402-YBN-RDC4, 494-0402-JBN-C7GQ).

\section{Availability of data and materials}

All data generated or analyzed during this study are included in this published article and its supplemental data files.

\section{Authors' contributions}

YZ performed experiments and wrote the paper, MH performed the GMP analysis, QL performed the transformation, LS performed the DNA methylation and small RNA analysis, XC performed the agronomic traits and end-use quality analysis, LL performed the SDS-PAGE analysis, YL performed field trails, $\mathrm{XJ}$ and $\mathrm{HL}$ designed the experiments and assisted in writing the paper.

Ethics approval and consent to participate

Not applicable.

\section{Consent for publication}

Not applicable.

\section{Competing interests}

The authors declare that they have no competing interests.

\section{Publisher's Note}

Springer Nature remains neutral with regard to jurisdictional claims in published maps and institutional affiliations.

\section{Author details}

${ }^{1}$ Institute of Cereal and Oil Crops, Hebei Academy of Agriculture and Forestry Sciences, 162 Hengshan Street, Shijiazhuang 050035, China. ${ }^{2}$ Institute of Genetics and Developmental Biology, Chinese Academy of Sciences, 1 Beichenxi Road, Beijing 100101, China.

Received: 26 July 2018 Accepted: 15 November 2018 Published online: 03 December 2018

\section{References}

1. Shewry P, Halford N, Tatham A. High molecular weight subunits of wheat glutenin. J Cereal Sci. 1992;15(2):105-20.

2. Payne PI, Law CN, Mudd EE. Control by homoeologous group 1 chromosomes of the high-molecular-weight subunits of glutenin, a major protein of wheat endosperm. Theor Appl Genet. 1980;58(3-4):113-20.

3. Lindsay MP, Skerritt JH. Immunocytochemical localization of gluten proteins uncovers structural organization of glutenin macropolymer. Cereal Chem. 2000;77(3):360-9.

4. Gianibelli MC, Gupta RB, Lafiandra D, Margiotta B, MacRitchie F. Polymorphism of high Mr glutenin subunits in Triticum tauschii: characterisation by chromatography and electrophoretic methods. J Cereal Sci. 2001:33(1):39-52.

5. Payne P, Holt L, Worland A, Law C. Structural and genetical studies on the high-molecular-weight subunits of wheat glutenin. Theor Appl Genet. 1981; 60(2):129-36.

6. Anjum FM, Khan MR, Din A, Saeed M, Pasha I, Arshad MU. Wheat gluten: high molecular weight glutenin subunits - structure, genetics, and relation to dough elasticity. J Food Sci. 2007;72(3):R56-63.

7. Roy N, Islam S, Ma J, Lu M, Torok K, Tomoskozi S, Bekes F, Lafiandra D, Appels R, Ma W. Expressed Ay HMW glutenin subunit in Australian wheat cultivars indicates a positive effect on wheat quality. J Cereal Sci. 2018;79: 494-500.

8. Tatham A, Marsh M, Wieser H, Shewry P. Conformational studies of peptides corresponding to the coeliac-activating regions of wheat a-gliadin. Biochem J. 1990;270(2):313-8.

9. Wieser H. Chemistry of gluten proteins. Food Microbiol. 2007;24(2):115-9.

10. Tatham AS, Shewry PR, Miflin BJ. Wheat gluten elasticity: a similar molecular basis to elastin? FEBS Lett. 1984;177(2):205-8.

11. Shewry PR, Sayanova O, Tatham AS, Tamas L, Turner M, Richard G, Hickman D, Fido R, Halford NG, Greenfield J. Structure, assembly and targeting of wheat storage proteins. J Plant Physiol. 1995;145(5-6):620-5.

12. Buonocore F, Bertini L, Ronchi C, Bekes F, Caporale C, Lafiandra D, Gras P, Tatham A, Greenfield J, Halford N. Expression and functional analysis of Mr58 000 peptides derived from the repetitive domain of high molecular weight glutenin subunit 1Dx5. J Cereal Sci. 1998;27(3):209-15.

13. Wan Y, Liu K, Wang D, Shewry PR. High-molecular-weight glutenin subunits in the Cylindropyrum and Vertebrata section of the Aegilops genus and identification of subunits related to those encoded by the Dx alleles of common wheat. Theor Appl Genet. 2000;101(6):879-84. 
14. De BA, Jouve N. Characterisation and analysis of new HMW-glutenin alleles encoded by the Glu-R1 locus of Secale cereale. Theor Appl Genet. 2003; 107(1):74-83.

15. Wang JR, Yan ZH, Wei YM, Zheng YL. Characterization of high-molecular-weight glutenin subunit genes from Elytrigia elongata. Plant Breed. 2006;125:89-95.

16. Vaccino P, Banfi R, Corbellini M, Pace CD. Improving the wheat genetic diversity for end-use grain quality by chromatin introgression from the wheat wild relative Dasypyrum villosum. Crop Sci. 2010;50(2):528-40.

17. Zhang R, Zhang M, Wang $X$, Chen P. Introduction of chromosome segment carrying the seed storage protein genes from chromosome $1 \mathrm{~V}$ of Dasypyrum villosum showed positive effect on bread-making quality of common wheat. Theor Appl Genet. 2014;127(3):523-33.

18. Hou W, Feng W, Yu G, Du X, Ren M. Cloning and functional analysis of a novel $x$-type high-molecular-weight glutenin subunit with altered cysteine residues from Aegilops umbellulata. Crop Pasture Sci. 2017;68(5):409-14.

19. Liu Z, Yan Z, Wan Y, Liu K, Zheng Y, Wang D. Analysis of HMW glutenin subunits and their coding sequences in two diploid Aegilops species. Theor Appl Genet. 2003;106(8):1368-78.

20. Shewry PR, Halford NG, Tatham AS, Popineau Y, Lafiandra D, Belton PS. The high molecular weight subunits of wheat glutenin and their role in determining wheat processing properties. Adv Food Nutr Res. 2003;45(3): 219-302.

21. Wang S, Yu Z, Cao M, Shen X, Li N, Li X, Ma W, Weißgerber H, Zeller F, Hsam $S$, et al. Molecular mechanisms of HMW glutenin subunits from 1s genome of Aegilops longissima positively affecting wheat breadmaking quality. PLoS One. 2013;8(4):e58947.

22. Wan Y, Yan Z, Liu K, Zheng Y, D'Ovidio R, Shewry PR, Halford NG, Wang D. Comparative analysis of the $\mathrm{D}$ genome-encoded high-molecular weight subunits of glutenin. Theor Appl Genet. 2005;111(6):1183-90.

23. Liang D, Tang JW, Peña RJ, Singh R, He XY, Shen XY, Yao DN, Xia XC, He ZH. Characterization of CIMMYT bread wheats for high- and low-molecular weight glutenin subunits and other quality-related genes with SDS-PAGE, RP-HPLC and molecular markers. Euphytica. 2010;172(2):235-50.

24. Hernández ZJE, Figueroa JDC, Rayas-Duarte P, Martínezflores HE, Arámbula GV, Luna GB, Peña RJ. Influence of high and low molecular weight glutenins on stress relaxation of wheat kernels and the relation to sedimentation and rheological properties. J Cereal Sci. 2012:55(3):344-50.

25. Vázquez D, Berger AG, Cuniberti M, Bainotti $C$, de Miranda MZ, Scheeren $P L$, Jobet C, Zúñiga J, Cabrera G, Verges R, et al. Influence of cultivar and environment on quality of Latin American wheats. J Cereal Sci. 2012;56(2): 196-203.

26. Peña E, Bernardo A, Soler C, Jouve N. Relationship between common wheat (Triticum aestivum L.) gluten proteins and dough rheological properties. Euphytica. 2005;143(1-2):169-77.

27. Liu W, Zhang Y, Gao X, Wang K, Wang S, Zhang Y, He Z, Ma W, Yan Y. Comparative proteome analysis of glutenin synthesis and accumulation in developing grains between superior and poor quality bread wheat cultivars. J Sci Food Agric. 2012;92(1):106.

28. He ZH, Liu L, Xia XC, Liu JJ, Peña RJ. Composition of HMW and LMW glutenin subunits and their effects on dough properties, pan bread, and noodle quality of chinese bread wheats. Cereal Chem. 2005;82(4):345-50.

29. Jood S, Schofield JD, Tsiami AA, Bollecker S. Effect of glutenin subfractions on bread-making quality of wheat. Int J Food Sci Tech. 2001;36(5):573-84.

30. Wang XL, Zhang YQ, Zhang B, Florides CG, Gao Z, Wang ZH, Zhang XK, Wei YM. Comparison of quality properties between high-molecular-weight glutenin subunits $5+10$ and $2+12$ near-isogenic lines under three common wheat genetic backgrounds. Cereal Chem. 2018;95(4):575-83.

31. Hernández-Estrada ZJ, Rayas-Duarte P, Cárdenas JDF. Creep recovery of wet gluten and high-molecular-weight glutenin subunit comosition: relationship with viscoelasticity of dough and breadmaking quality of hard red winter wheat. Cereal Chem. 2017;94(2):223-9.

32. Peng Y, Yu K, Zhang Y, Islam S, Sun D, Ma W. Two novel y-type high molecular weight glutenin genes in Chinese wheat landraces of the Yangtze-River region. PLoS One. 2015;10(11):e0142348.

33. Lafiandra D, D'Ovidio R, Porceddu E, Margiotta B, Colaprico G. New data supporting high Mr glutenin subunit 5 as the determinant of quality differences among the pairs 5 + 10 vs. 2 + 12. J Cereal Sci. 1993;18(2):197-205.

34. Shewry P, Gilbert S, Savage A, Tatham A, Wan YF, Belton P, Wellner N, D'Ovidio R, Békés F, Halford N. Sequence and properties of HMW subunit $1 \mathrm{~B} \times 20$ from pasta wheat (Triticum durum) which is associated with poor end use properties. Theor Appl Genet. 2003;106(4):744.
35. Blechl A, Lin J, Nguyen S, Chan R, Anderson OD, Dupont FM. Transgenic wheats with elevated levels of Dx5 and/or Dy10 high-molecular-weight glutenin subunits yield doughs with increased mixing strength and tolerance. J Cereal Sci. 2007:45(2):172-83.

36. Ragupathy R, Naeem HA, Reimer E, Lukow OM, Sapirstein HD, Cloutier S. Evolutionary origin of the segmental duplication encompassing the wheat GLU-B1 locus encoding the overexpressed $\mathrm{B} \times 7$ ( $\left.\mathrm{B} \times 7^{\mathrm{OE}}\right)$ high molecular weight glutenin subunit. Theor Appl Genet. 2008;116(2):283-96.

37. Gao X, Liu T, Ding M, Wang J, Li C, Wang Z, Li X. Effects of HMW-GS Ax1 or Dx2 absence on the glutenin polymerization and gluten micro structure of wheat (Triticum aestivum L.). Food Chem. 2017:240:626-33.

38. Yue SJ, Li H, Li YW, Zhu YF, Guo JK, Liu YJ, Chen Y, Jia X. Generation of transgenic wheat lines with altered expression levels of 1Dx5 high-molecular weight glutenin subunit by RNA interference. J Cereal Sci. 2008;47(2):153-61.

39. Ma M, Yan Y, Huang L, Chen M, Zhao H. Virus-induced gene-silencing in wheat spikes and grains and its application in functional analysis of HMWGS-encoding genes. BMC Plant Biol. 2012;12(1):141.

40. Hu X, Dai S, Pu Z, Liu D, Pu Z, Jiang J, Wei Y, Wu B, Lan X, Zheng Y. Quality of synthetic hexaploid wheat containing null alleles at Glu-A1 and Glu-B1 loci. J Genet. 2013;92(2):241-5.

41. Cogoni C, Macino G. Post-transcriptional gene silencing across kingdoms. Curr Opin Genet Dev. 2000;10(6):638-43.

42. Dehio C, Schell J. Identification of plant genetic loci involved in a posttranscriptional mechanism for meiotically reversible transgene silencing. Proc Natl Acad Sci. 1994;91(12):5538-42.

43. Napoli C, Lemieux C, Jorgensen R. Introduction of a chimeric chalcone synthase gene into petunia results in reversible co-suppression of homologous genes in trans. Plant Cell. 1990;2(4):279-89.

44. Smith C, Watson C, Bird C, Ray J, Schuch W, Grierson D. Expression of a truncated tomato polygalacturonase gene inhibits expression of the endogenous gene in transgenic plants. Mol Gen Genet. 1990;224(3):477-81.

45. Alvarez ML, Guelman S, Halford NG, Lustig S, Reggiardo Ml, Ryabushkina N, Shewry P, Stein J, Vallejos RH. Silencing of HMW glutenins in transgenic wheat expressing extra HMW subunits. Theor Appl Genet. 2000;100(2):319-27.

46. He GY, Jones HD, D'Ovidio R, Masci S, Chen M, West J, Butow B, Anderson OD, Lazzeri P, Fido R. Expression of an extended HMW subunit in transgenic wheat and the effect on dough mixing properties. J Cereal Sci. 2005;42(2):225-31.

47. Uthayakumaran S, Lukow OM, Jordan MC, Cloutier S. Development of genetically modified wheat to assess its dough functional properties. Mol Breed. 2003;11(4):249-58.

48. Watt F, Molloy PL. Cytosine methylation prevents binding to DNA of a HeLa cell transcription factor required for optimal expression of the adenovirus major late promoter. Genes Dev. 1988;2(9):1136-43.

49. Jones L, Ratcliff F, Baulcombe DC. RNA-directed transcriptional gene silencing in plants can be inherited independently of the RNA trigger and requires Met1 for maintenance. Curr Biol. 2001;11(10):747-57.

50. $\mathrm{Ng} \mathrm{HH}$, Adrian B. DNA methylation and chromatin modification. Curr Opin Genet Dev. 1999;9(2):158-63.

51. Kass SU, Pruss D, Wolffe AP. How does DNA methylation repress transcription? Trends Genet. 1997;13(11):444-9.

52. Baulcombe D. RNA silencing in plants. Nature. 2004:431(7006):356-63.

53. Bouché N, Lauressergues D, Gasciolli V, Vaucheret H. An antagonistic function for Arabidopsis DCL2 in development and a new function for DCL4 in generating viral siRNAs. EMBO J. 2006;25(14):3347-56.

54. Matzke MA, Birchler JA. RNAi-mediated pathways in the nucleus. Nat Rev Genet. 2005;6(1):24-35.

55. Bartel DP. MicroRNAs: genomics, biogenesis, mechanism, and function. Cell. 2004;116(2):281-97.

56. Meister $\mathrm{G}$, Tuschl T. Mechanisms of gene silencing by double-stranded RNA. Nature. 2004:431(7006):343-9.

57. Tang G. siRNA and miRNA: an insight into RISCs. Trends Biochem Sci. 2005; 30(2):106-14.

58. Hamilton AJ, Baulcombe DC. A species of small antisense RNA in posttranscriptional gene silencing in plants. Science. 1999;286(5441):950-2.

59. Hewezi T, Piya S, Qi M, Balasubramaniam M, Rice JH, Baum TJ. Arabidopsis miR827 mediates post-transcriptional gene silencing of its ubiquitin E3 ligase target gene in the syncytium of the cyst nematode Heterodera schachtii to enhance susceptibility. Plant J. 2016;88(2):179-92.

60. Goesaert H, Brijs K, Veraverbeke WS, Courtin CM, Gebruers K, Delcour JA. Wheat flour constituents: how they impact bread quality, and how to impact their functionality. Trends Food Sci Technol. 2005;16(1):12-30. 
61. Graveland A, Bosveld P, Lichtendonk WJ, Marseille JP, Jhe M, Scheepstra A A model for the molecular structure of the glutenins from wheat flour. J Cereal Sci. 1985;3(1):1-16

62. Pirozi M, Margiotta B, Lafiandra D, MacRitchie F. Composition of polymeric proteins and bread-making quality of wheat lines with allelic HMW-GS differing in number of cysteines. J Cereal Sci. 2008;48(1):117-22.

63. Don C, Mann G, Bekes F, Hamer RJ. HMW-GS affect the properties of glutenin particles in GMP and thus flour quality. J Cereal Sci. 2006;44(2): $127-36$.

64. Lindsay MP, Skerritt JH. The glutenin macropolymer of wheat flour doughs: structure-function perspectives. Trends Food Sci Technol. 1999;10(8):247-53.

65. Wieser $\mathrm{H}$, Kieffer R. Correlations of the amount of gluten protein types to the technological properties of wheat flours determined on a micro-sale. $J$ Cereal Sci. 2001;34(1):19-27.

66. Tatham AS, Shewry PR. The S-poor prolamins of wheat, barley and rye. J Cereal Sci. 1995;22(1):1-16.

67. Gil-Humanes J, Pistón F, Rosell CM, Barro F. Significant down-regulation of $\gamma$-gliadins has minor effect on gluten and starch properties of bread wheat. J Cereal Sci. 2012;56(2):161-70.

68. van den Broeck HC, van Herpen TW, Schuit C, Salentijn EM, Dekking L, Bosch D, Hamer RJ, Smulders MJ, Gilissen L, van der Meer IM. Removing celiac disease-related gluten proteins from bread wheat while retaining technological properties: a study with Chinese spring deletion lines. BMC Plant Biol. 2009;9(1):41.

69. Pistón F, Gil-Humanes J, Rodríguez-Quijano M, Barro F. Down-regulating Ygliadins in bread wheat leads to non-specific increases in other gluten proteins and has no major effect on dough gluten strength. PLoS One. 2011;6(9):e24754

70. Peng J, Xia Z, Chen L, Shi M, Pu J, Guo J, Fan Z. Rapid and efficient isolation of high-quality small RNAs from recalcitrant plant species rich in polyphenols and polysaccharides. PLoS One. 2014;9(5):e95687.

71. Yu Z, Han C, Yan X, Li X, Jiang G, Yan Y. Rapid characterization of wheat low molecular weight glutenin subunits by ultraperformance liquid chromatography (UPLC). J Agric Food Chem. 2013;61(17):4026-34

72. Dong K, Hao CY, Wang AL, Cai MH, Yan YM. Characterization of HMW glutenin subunits in bread and tetraploid wheats by reversed-phase highperformance liquid chromatography. Cereal Res Commun. 2009:37(1):65-73.

73. Daniel C, Triboi E. Effects of temperature and nitrogen nutrition on the accumulation of gliadins analysed by RP-HPLC. Funct Plant Biol. 2001;28(28): 1197-205.

74. Han C, Lu X, Yu Z, Li X, Ma W, Yan Y. Rapid separation of seed gliadins by reversed-phase ultra performance liquid chromatography (RP-UPLC) and its application in wheat cultivar and germplasm identification. Biosci Biotechnol Biochem. 2015;79(5):808-15.

75. Don C, Lichtendonk W, Plijter JJ, Hamer RJ. Glutenin macropolymer: a gel formed by glutenin particles. J Cereal Sci. 2003;37(1):1-7.

Ready to submit your research? Choose BMC and benefit from:

- fast, convenient online submission

- thorough peer review by experienced researchers in your field

- rapid publication on acceptance

- support for research data, including large and complex data types

- gold Open Access which fosters wider collaboration and increased citations

- maximum visibility for your research: over $100 \mathrm{M}$ website views per year

At $\mathrm{BMC}$, research is always in progress.

Learn more biomedcentral.com/submissions 